\title{
Integration of Inquiry-Based Learning and Ongoing Assessment to Develop English Essay Writing in Upper Intermediate Level
}

\author{
Rabih Joseph Nabhan \\ Holy Spirit University of Kaslik (USEK), Kaslik, Lebanon \\ Email: rabihnabhan@usek.edu.lb
}

How to cite this paper: Nabhan, R. J. (2017). Integration of Inquiry-Based Learning and Ongoing Assessment to Develop English Essay Writing in Upper Intermediate Level. Open Journal of Modern Linguistics, 7, 90-107.

https://doi.org/10.4236/ojml.2017.72008

Received: February 18, 2017

Accepted: April 17, 2017

Published: April 20, 2017

Copyright $\odot 2017$ by author and Scientific Research Publishing Inc. This work is licensed under the Creative Commons Attribution International License (CC BY 4.0).

http://creativecommons.org/licenses/by/4.0/

\begin{abstract}
Many students of secondary classes in French medium schools struggle to write fluently and accurately as they approach university English entrance exams. However, very few students succeed in efficiently acquiring the necessary writing skills in due time. To investigate this deficiency, this study was conducted. The aim of this action research was to explore the impact of integrating Inquiry-Based Learning Approach (IBLA), ongoing assessment, and blogging to solve the problems students face when they write essays for varied purposes. The study was performed on two private French medium schools. In each school, the participants were divided into two groups: one experimental and one control. Both groups were taught the same essay genres. However, the experimental groups in both schools were taught by means of integrating the Inquiry-Based Learning Approach and ongoing assessment. On the other hand, the control groups continued using the conventional techniques. At the end of the instruction, a summative test took place. The results were analyzed quantitatively and qualitatively. The analysis of the results showed that integrating ongoing assessment and IBLA resulted in better scores with the experimental groups.
\end{abstract}

\section{Keywords}

Essay Writing, IBLA, Ongoing Assessment, Blog, Deficiency, Quantitative and Qualitative Analysis

\section{Introduction}

Students of secondary classes struggle to improve their essay writing as they approach university entrance exams. However, their efforts are useless because they lack the time and the needed writing skills. To mend this deficiency, on- 
going assessment and Inquiry-Based Learning Approach (IBLA) were introduced to second foreign language students of two French education schools: College des Soeurs des Saints Coeurs, Jbeil and College des Saints des Saints Coeurs, Beit Chabab. The project was carried out during a full academic year in which assessment and IBLA are integrated to form a nucleus promoting different types of essay. To improve collaboration and assessment outside the classroom, a blog was utilized by the participants to assist, discuss, and cooperate from their homes.

Deboer (2006) believes that similar to researchers who perform inquiries and examinations in laboratories, students can inquire and investigate in their classrooms. As a result of reflection and investigation, they can assist each other and thus learn from each other. Falk and Margolin (2005) consider that the InquiryBased Approach teaches learners to raise questions, argue problems, and find solutions through team and group work. They add that during the inquiry process, the participants assess themselves and each other. Cam (2006) argues that the best solution to writing problems is asking the right questions, investigating, and cooperating to evaluate answers and come up with the best solutions. In the inquiry process ongoing assessment plays a vital role because the process is continuous and requires constant guidance and evaluation (Kuhlthau, Maniotes, \& Caspari, 2007). In addition, the inquiry process consists of activities based on continuous engagement and self and peer assessment (Coffman, 2009). For assessment to be continuous it is supposed to be performed in the classroom as well as at home. Blood (2000) and Hewitt (2005) introduce blogs which according to them are effective grounds for learners to collaborate and assist from homes. By means of blogs, learners collaborate and learn during interactions and create more knowledge construction (Hou, Chang, \& Sung, 2009).

In the context of integrating assessment through IBLA, the following research questions arise:

1) How efficient will ongoing assessment be through the implementation of the IBLA approach in essay writing?

2) Can the blog be an effective assessment tool for inquiry-based strategies outside the classroom? If yes, how?

3) How does the integration of IBLA, ongoing assessment, and technology enhance metacognition?

4) How can the integration of ongoing assessment and IBLA tasks help promote the targeted language areas (content, organization, conventions, voice, word choice, and sentence fluency)?

\section{Review of Literature}

\subsection{Writing and Writing Difficulties}

The writing skill, as the other language skills, has suffered with the changes in educational systems and the search for an ideal approach (Clark, 2008). Composition writing is a must and it is required in every university entrance exam, whether English or French education universities. Greene and Lidinsky (2012), 
in their Preface for Instructors, state that "academic writing is the challenging intellectual price of admission to college" (p. v). They add that students must not only write well but also think in complex new ways. The new ways of thinking are needed for both entrance exams and college lessons. Therefore, they are to be learned and mastered before applying to university (Greene \& Lidinsky, 2012).

Laksmi (2006) states that students of an EFL writing classroom experience difficulties in getting ideas, organizing ideas and developing details, writing grammatically correct sentences, choosing correct words and structuring ideas in correct sentences, and maintaining paragraph unity. He adds that writing lessons were and are still teacher-centered where the instructor does the entire job and the learner only listens and applies. Teacher-centered instruction, according to Kauchak and Eggen (2003), is appropriate when the content is specific and well defined when the content is expected to be mastered by all the students, and when the content is difficult to be mastered by the students on their own.

Greene and Lidinsky (2012) consider inquiry as a basis to write academically. They believe that every piece of writing must begin with questions which lead to more complex insights. To them, the ability to ask good questions is equally valuable in daily life. The question that arises in this context is whether the Inquiry-Based Learning Approach, if implemented in a writing classroom, will lead to overcoming the writing obstacles.

\subsection{Inquiry-Based Learning Approach}

The Inquiry Approach started with science. Scientists base their knowledge of the natural world on observation and investigation of data (Bybee, 2006; Deboer, 2006). Just as scientists "conduct inquiries and investigations in the laboratory, at field sites, in the library, and in discussions with colleagues, students engage in similar activities in inquiry-based classrooms" (Deboer, 2006: p. 17).

Konicek-Moran (2008) links inquiry-based science and literacy as both hold the process of "observing, classifying, inferring, predicting, and communicating" (p. 17). He adds that both science and literacy are to understand a certain concept and then to have the ability to use. In other words, they are supposed to have meaning in everyday life. Kuhlthau, Maniotes, and Caspari (2007) state that "through Guided Inquiry students gain the ability to use tools and resources for learning in and beyond the information age while they are learning the content of the curriculum and meeting subject area curriculum standards" (p. 2).

Therefore, to help students develop their writing skills, Inquiry-Based Learning Approach, a complex process that "refers to instructional practices designed to promote the development of high order intellectual and academic skills through student-driven and instructor-guided investigation of student-generated questions" (Cox, Webber, Levy \& Stordy, 2007: p. 1), is introduced. The inquiry process involves learners so that learning becomes a process which makes them acquire deeper knowledge of the material being taught (Coffman, 2009). In fact, students interact by asking questions to increase comprehension of the material and at the same time form their own knowledge. 
According to Kahn and O'Rourke (2005), the IBLA is meant to help students learn for life. They need to cultivate curiosity, tackle complex problems and know the significance of working with others to approach difficult situations. They add that teachers must promote the students' voice by encouraging them to work for themselves because that is what life is like. Kuhlthau, Maniotes, and Caspari (2007) mention that many teachers in many educational establishments are now turning to inquiry learning in different subjects to meet the challenge of educating their students for lifelong learning. There must be a change from being spoon-fed with information into forming their opinions (Bruce \& Bishop, 2001). This type of cooperative/active learning, according to Johnson, Johnson and Smith (1991), is the instructional use of small heterogeneous groups so that learners work together to maximize their own and each other's' learning

Awakening learners' own questions is a unique and effective quality of instruction within the inquiry framework (Falk \& Margolin, 2005). Thus, students, as Falk and Margolin (2005) state, should learn how to investigate to find solutions to problems raised, argue points of view, and assess materials, learning/teaching strategies, self, and peers by asking questions and submitting adequate responses relevant to the topic and subject under study. Inquiry learning is not simply answering questions, but investigation, search, quest, research, pursuit, and study (Kuhlthau, Maniotes, \& Caspari, 2007). Through inquiry-oriented tasks, learners become actively involved in chores which require them to solve problems through implementing skills such as observing, collecting, analyzing, and synthesizing.

For inquiry to be successful, students must assume leading roles in their learning process (Coffman, 2009). Our students must learn to think for themselves to any significant degree, and as a result, we are developing and preparing in them the attitudes and habits that characterize people who have learnt to think for themselves (Cam, 2006). In fact, inquiry-based learning is effective in shaping students' abilities to think critically and apply their knowledge (Chung \& Beham, 2010).

In a research conducted by Falk and Blumenreich (2005), Sue and Susan (two language teachers) implemented the IBLA in their classes and could manage successfully their students learning by the use of questioning techniques that "led students to bigger issues that carried them across different units of study in their investigations" (p. 173).

\subsection{Ongoing Assessment}

According to Lippman (2008), assessment is the attempt to measure how much a learner has acquired from a given program. She adds that this kind of assessment is useful to programs, yet it does not provide teachers with much information about individual students. On the other hand, according to Lippman (2008), ongoing or formative assessment is the continuous follow up and constant evaluation of a student's work and its main goal is to help the student improve his/her writing and writing ability. 
Effective assessment should have a dual purpose by providing the teacher with insight into the learners' understanding, and by promoting further learning by providing feedback to the students themselves (Katz \& Olson, 2006). Tests provide information to the instructors about the students, but rarely provide real feedback to the students. What learners get at the end of a writing test is vague statements such as "Good job!" and "Way to go!" which maybe quick to jot down but do not provide meaningful feedback to the students seeking to develop their performance (Katz \& Olson, 2006).

As Brown (2002) states, the language teacher is encouraged to engage in a careful process of diagnosis, treatment, and assessment. This process enables the teacher to account for the different needs among the learners, devise effective pedagogical treatment to remedy the deficiency, and to assess what went right and what went wrong in a given lesson. Assessment can be from the beginning of the process till its end, for assessment "provides us with opportunities to plan effectively and to set goals for instruction" (Cappellini, 2005: p. 243).

\subsection{Integration of Inquiry-Based Learning and Ongoing Assessment}

"In the inquiry/discovery classroom, assessment takes on special meaning because the process is ongoing and measures both content mastery and level of initiative students attain in directing their own education" (Sutman, Schmuchler, \& Woodfield, 2008: p. 141). Thus, guided inquiry requires ongoing assessment (Kuhlthau, Maniotes, \& Caspari, 2007) because assessment "in combination with an inquiry-based learning activity enhances students' learning and rehearses them for their future roles" (Chung \& Beham, 2010: p. 24). Inquiry activities support learning through engagement which part of it comes through continued assessment (Coffman, 2009).

Katz and Olson (2006) talk about Mrs Jackson, who used a multifaceted assessment to engage her students in many ways. She included tests and used students' performances so that students can show their comprehension in many ways. In other words, Mrs Jackson implemented both the summative and formative types of assessment.

According to Coffman (2009), assessment takes many forms. It can be informal through observations, questioning, group work, and think-pair-share. It can be formal through quizzes and project performances. However, the key to any effective assessment "is to incorporate assessments throughout your unit to ensure student understanding and not only at the end of a unit through a summative evaluation" (Coffman, 2009: p. 115). Therefore, to seek knowledge for overcoming the writing gaps, the IBLA integrates formative and summative assessments. The former, as indicated by Linn and Miller (2005), is the continuous type that monitors students during the learning process and provides feedback to both students and teachers. The latter "typically comes at the end of a course (or unit) of instruction" (Linn \& Miller, 2005: p. 36). Therefore, as Linn and Miller (2005) and Lippman (2008) state the ongoing or formative assessment is 
based on informal settings i.e. no formal quizzes, to function as a ground for the practice tasks of each type of essay. The summative assessment is a test given after each essay type.

In addition to assessment by the teacher, self and peer assessment are important. One type of assessment that has been shown to raise students' achievement significantly is student self-assessment (Black \& William, 1998; Chappuis \& Stiggins, 2002; Rolheiser \& Ross, 2001). Nunan (2004) mentions that assessment through IBLA helps the learners assess themselves as well as their classmates. This is particularly significant in classrooms where teachers want to encourage autonomy, which is a key for future success in life issues (Nunan, 2004). Cram (1995) advocates the value of self-assessment in that it involves students in their own learning process.

Ideally, as Chung and Beham (2010) state, students will become self-directed learners who can reflect, criticize themselves, and give constructive criticism to others. They add that this is what life is like and our learners are supposed to practice their future roles starting from the classroom.

Lassonde and Israel (2010) talk about Molly Fanning and Brigit Schmidt, two teachers, who when teaching writing asked themselves how their assessment of student writing could encourage not only a better final product but also nurture each student's writing process. They wanted their assessment to give their learners credit for the work of getting to the final product, not simply be a grade on a piece of writing. To achieve that, their students became invested in their writing because they were allowed to negotiate how they would meet the criteria.

\subsection{Technology, Specifically Blogging in Developing and Assessing Writing}

Computer technology or information and communication technology (ICT) has had a major influence on our lives in the last two decades. Computer software and the Internet with its unique features have become major tools to support education. According to Dodigovic (2005), technology "can conform to any linguistic or language learning theory" (p. 4). She adds that the use of any computer program to facilitate any approach is a reflection of the author's view of language learning and this gives importance to thinking that Computer Assisted Language Learning (CALL) should be generously used for testing of theory and concepts.

Chapelle (2003) points out that teachers agree that their students need to practice English outside their classroom if they want to improve their communication competence. Blogs are personal online webpages or websites on which an individual can record opinions and other things (Oxford Dictionary: http://oxforddictionaries.com/definition/english/blog). Anyone can post and read on blogs (Hewitt, 2005). Therefore, blogs can be a medium that facilitates students' interaction from their homes. On the class blog, the students will post links and add remarks to assist each other improve the essay genre organization, content, conventions, voice, word choice, and sentence fluency. 
In addition to providing teachers with a tool for communicating with students, blogs are highly motivating for students to read and write (Betts \& Glogoff, 2005; Crie, 2006). They are effective forums for collaboration and discussion and can act as powerful tools that enable scaffolded learning (Crie, 2006). Blood (2000) concedes that a blog is a very powerful medium that can change the status of both its readers and writers from "consumers" to "creators". Blood believed that weblogs could be one of the solutions for the "crippling effects of a media-saturated culture" (p. 33). The blog creates a learning environment that is structured and the learners are provided with cognitive tools for specific activities performed on the blog.

In a book entitled Always On, Baron (2008) listed many reasons for people to blog: creative self-expression, sharing knowledge, exchanging opinions with others, thinking in writing, and releasing emotions. The writer indicated that, for bloggers, "the medium constitutes an important platform for free speech" (p. 113). Betts and Glogoff (2005), talked about several studies that supported the claim that blogging can facilitate language learning. They say that blogs have proven to be good educational tools as they allow for effective interaction, which promotes students' learning motivations. Godwin-Jones (2003) remarked the opportunities a blog can grant a learner, especially freeing a student from the limitations of the conventional classroom and address a real-life audience. He also noticed that self-publishing encourages autonomy, ownership, and responsibility.

Talented teachers, according to Blake (2008), "actively seek to provide opportunities for their students to engage in collaborative interactions" (p. 70). Godwin-Jones (2006) listed many advantages of using blogging as a collaborative interactive learning tool.

$\mathrm{Wu}$ (2007) believed that frequent writing, especially, writing for an audience and writing "that matters", improves learners' competence. The researcher mentioned that further benefits could occur when learners look up English words from dictionaries or use Internet resources to help them refine and express their ideas clearly and correctly. The writer found that $91 \%$ of the respondents in his study said that they consulted dictionaries, checked online references or asked someone before they posted to make sure their materials were reliable and accurate.

Another study on using blogging in English language teaching was conducted by Genzola (2010) at Jilin University in China. The study showed that $95.37 \%$ of the participants' attitude was highly positive towards using web blogging as language learning tool.

According to Sun (2009), students observed blogging "not only as a means of learning, but also as a means of self-presentation, information exchange, and social networking". Moreover, Sun realized that blogs were perceived as "a dynamic forum that fosters extensive practice, learning motivation, authorship, and development of learning strategies" (p. 99).

To conclude this section, the IBLA prepares students for life through a variety 
of tasks that teach them to ask, investigate, reflect, create and discuss (Kahn \& O'Rourke, 2005). These tasks help assess students and students to assess themselves. The blog, as an assessment tool, can have essential benefits in creating a motivating medium on which IBLA takes place. Therefore, if teachers can integrate assessment, IBLA, and blogging, they can keep track of their students' performance and guide them in a variety of tasks continuously and in different contexts. In the study, ongoing assessment consisted of different tasks which the learners performed. Each task was inquiry-based and the home portion of the assessment was through the blog.

\section{Methodology}

The action research is the style of the educational research utilized in this study. According to O'Brien (2001), Mertler (2006), and Dana \& Yendol-Hoppey (2008), it is often the case that those who apply this approach are practitioners who wish to improve understanding of their practice. Henning, Stone, \& Kelly (2009) cite Zeichner \& Noffke (2001) that action research has proved to improve student achievement, provide opportunities for professional development, and help teachers make their practice more explicit. Julie Nora (1999) applied an action research on her class and had a chance to study her own practices and realized what worked and what did not work with her students. She could assess her students' current levels, conduct new methods and measure the results.

As described by Zuber-Skerritt (1996) and Cohen, Manion, \& Morrison (2000), action research is a powerful tool for change and improvement at the local level. It is "dynamic because of its activist stance, its focus on the possibility of change" (Somekh, 2011: p. 34). According to O'Brien (2001), action research is identifying a problem and doing something to solve it; it is learning by doing. Cohen et al. (2000) add that "Action research may be used in almost any setting where a problem involving people, tasks and procedures cries out for solution, or where some change of feature results in a more desirable outcome" (p. 226).

According to Mac Naughton and Hughes (2008), action research resembles the Inquiry-Based Learning by seeking to create new ways of thinking and having the cycle of asking questions, collecting information, creating new ideas, discussing new ideas with others, and reflecting on what has been learnt. They both follow the cycle illustrated Figure 1.

In the inquiry process, the learners implement what is learnt to attain improvement. Likewise, in the action research the researcher "will take actions and implement improvements based on what is learned from the research" (Mims, 2009: p. 20).

As mentioned earlier, inquiry-based learning functions as a creator of new knowledge (Coffman, 2009). Action research shares this quality as it "creates not just change in current practices, but also new knowledge about those practices" (Mac Naughton \& Hughes, 2008: p. 23). The new knowledge is established as a basis for improvement and a mode for future development. 


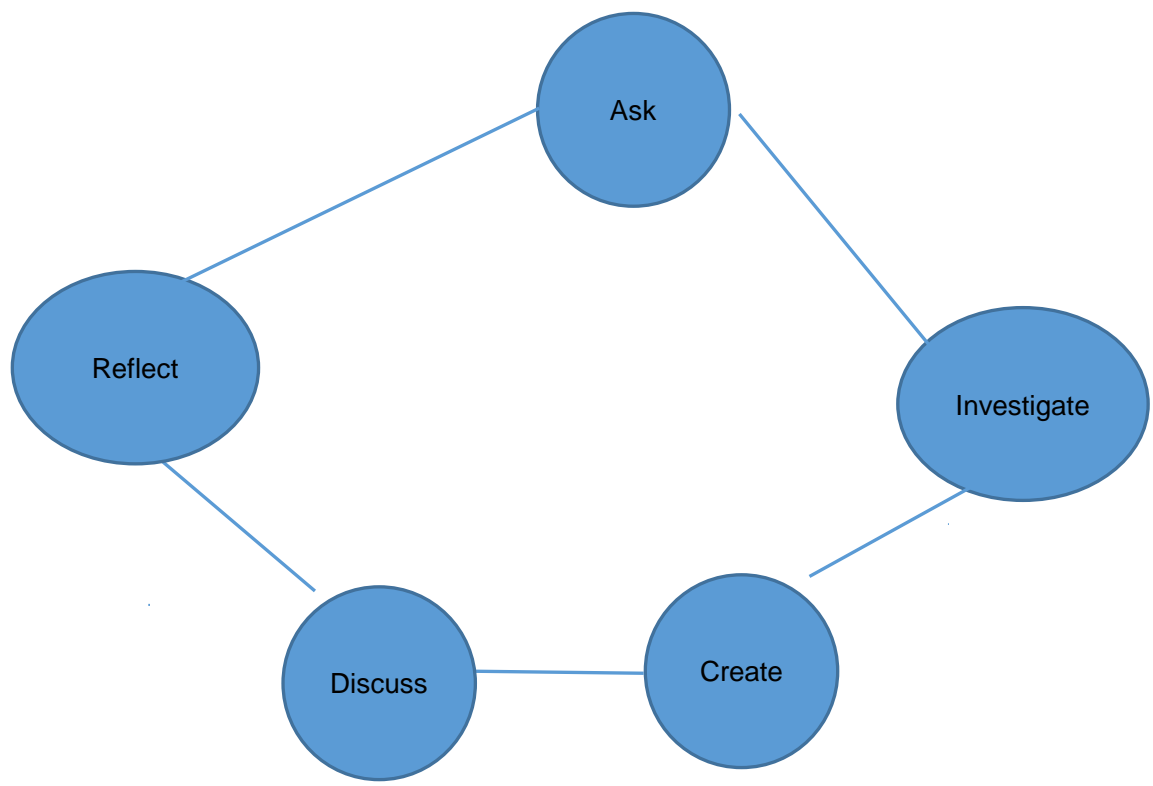

Figure 1. Action research and inquiry-based learning cycle.

\subsection{Participants}

Two schools participated in this study, College des Soeurs des Saints Coeurs, Jbeil (SSCCJbeil) and College des Soeurs des Saints Coeurs, Beit Chabab (SSCC Beit Chabab). Three Grade 9 classes were from SSCC, Jbeil, and two were from SSCC, Beit Chabab. The participants were about 160 as the number of students in each class in SSCCJbeil and SSCC Beit Chabab was 38 and 25 respectively.

Since there were three grade 9 classes in SSCCJbeil, a pre-test was held to select the two classes that had the least mean difference. The pre-test was also held in SSCC Beit Chabab to insure that the participating classes were of similar level in composition writing.

The final participants were sections $\mathrm{A}$ and $\mathrm{C}$ from SSCCJbeil and A and B from SSCC Beit Chabab. As a result, the final number of participants in the study was exactly 124 . The experimental classes were randomly selected after the results of the pre-test. Sections A from both schools were the experimental classes, while sections C and B from SSCCJbeil and SSCC Beit Chabab respectively were the control classes. The experimental class of SSCCJbeil was divided into 8 groups, 5 students in 7 groups and 4 in 1 group (Section A had 39 students). The experimental class of SSCC Beit Chabab was divided into 5 groups, 5 students in 3 groups and 4 students in 2 groups (Section A had 23 students). The level of students in essay writing varied on a scale of weak, average, and good.

\subsection{Procedure}

The plan is meant to have Inquiry-Based Learning tasks which include questioning, planning and predicting, investigating, recording and reporting, and reflecting. According to Nunan (2004), the concept of task is a prominent element in learner assessment and it has influenced education in both ESL and EFL settings. Inquiry-based language tasks are essential in on-going assessment. 
The process was of four phases: plan, act, observe, and reflect. Kemmis and McTaggart (1992), O’Brien (2001), Cohen, Manion, and Morrison (2000), and Mertler (2006) argue that to do any action is to plan, act, observe, and reflect. The plan was the pre-action step which handled the pre-test, selection of classes, division of groups, and establishing the blog. The action part was the beginning of the instruction and the implementation of the new method. The observation phase dealt with systematic collection of data. Information was gathered using the research tools. Finally, the reflection part was to analyze the collected data which could result in conclusions.

The students of the control group were given instructions and information following the curriculum, while the experimental group followed the same procedures and added to them tasks in which the Inquiry-Based Learning Approach was implemented.

\subsection{Data Collection}

Data collection is an integral part in any research. The researchers are to gather information using specific tools that can aid them gain insight of their study and thus lead them to a final conclusion. According to Cohen, Manion, and Morrison (2007), reliability and validity cannot be completely achieved in a research. Thus, they were addressed by using different tools of data collection. Scholz and Tietje (2002) and Cohen et al. (2007) confirm that triangulation or "convergence of methods" is an effective technique to validate collection of data. Triangulation is the use of two or more methods of data collection in the study of a certain aspect of human behaviour. It is an imperative feature of a research in the process of analysis and interpretation (McDonough \& McDonough, 1997). Therefore, to ensure validity of collecting data, seven methods of collection were utilized: tests, observation, interviews, questionnaires, accounts, portfolios, and correction rubric.

Testing, according to Cohen et al. (2000) and Marczyk, DeMatteo, and Festinger (2005), is a powerful method of data collection. For summative assessment of each essay type, a graded test was held, while for formative assessment ungraded tests were performed.

Observation according to Cohen et al. (2000), Wisker (2001), and Marczyk et al. (2005) is a versatile approach of data collection as it can aid the researcher to gain insight into a situation. It gives the researcher the opportunity to study and analyse events from a close distance and consequently makes him aware of important factors related to his study.

The third method in the convergence of methods or triangulation is the interview. The in-depth or unstructured interviews which "are one of the main methods of data collection used in qualitative research" (Legard, Keegan, \& Ward, 2003: p. 138) were utilized. This kind of interview is like a conversation and has a flexible structure to permit topics to be covered in the order most suited to the interviewee. In addition, this kind can allow the use of follow-up questions which, as Wisker (2001) argues, can help obtain deeper understanding 
of the case and refine an area if there are misunderstandings.

The questionnaire is a fundamentally useful tool to collect data (Wilson \& McLean, 1994). It can be used to gather information about large number of participants or small groups (McNabb, 2010). The aim of this instrument was to collect data from the students before the research, after the summative test on each type of essay, and at the end of the research.

The fifth instrument is accounts, which are seen within the context of social episodes (a fragment of social life). Accounts are when the researcher records the behaviour and everything related to it such as gesture and speech, in addition to the feelings and intentions of the persons under study. According to Cohen et al. (2000), the big advantage of accounts lies in the distinctive insights that are made available to the researcher when he/she analyses accounts of social episodes.

The sixth instrument of collection is portfolios. An important dimension of portfolio assessment is that it should actively involve the students in the process of assessment (Tierney, Carter, \& Desai, 1991). Students' essays were included in the portfolios so that the changes were observed from one essay to another. The portfolio functioned as an assessment tool for the students and as an instrument to collect data related to improvement and progress in the six traits. According to Frazier \& Paulson (1992), the portfolio can serve as a motivating tool for learners to assess themselves. The students relied on their portfolios to check their improvement in every essay and to check the type of mistakes that needed to be worked on while writing the informal essay's drafts. They also used the portfolios to discuss and reflect on individual's mistakes through the cooperative inquiry group work.

Finally, a correction rubric was utilized as the essays were corrected analytically. The rubric consists of six categories: content, organization, conventions, voice, word choice, and sentence fluency. The rubric's scale is of six levels: beginning, emerging, developing, proficient, strong, and exemplary. Each level has its specific criteria which can measure a piece of writing with a high degree of accuracy.

\subsection{Data Analysis}

The variety of perspectives and units of analysis which can achieve a complete understanding requires the integration of both qualitative and quantitative methods (Scholz and Tietje, 2002; Ritchie, 2003). When used together, the two methods can offer a powerful resource to inform and illuminate strategies and practices. Therefore, the data were analysed both quantitatively and qualitatively. To measure the students' writing development, the results were first analyzed quantitatively and then backed up qualitatively.

For quantitative analysis, the summative testing records were numerically analysed using the SPSS (Statistical Package for the Social Sciences) to show and measure the mean and significant differences between the scores of the control and experimental groups. The SPSS was utilized as it could allow for in-depth 
data access and accuracy. It is an important statistics software program that allows the user to easily perform accurate statistical analysis (Marques de Sa, 2003). Since we were comparing two samples (two classes each time from SSCCJbeil and SSCC Beit Chabab), we applied Paired-Samples T-Test tables, figures, and charts were used to display the transformation. The data that were analysed were the score results of each class to show the change that had occurred between the pre-test and the three summative tests.

For qualitative analysis, the data collected in the seven methods of collection were discerned, examined, and interpreted. The aim of this kind of analysis was a complete, detailed description of the changes that occurred from the beginning of the study to its end. Such changes are related to essay content, organization, conventions, voice, word choice, and sentence fluency.

In addition, portfolios of all the essays (pre-test and three summative tests) for all the students were created. After collecting the portfolios, for text analysis random samples were selected for error analysis and development in the six traits. They were categorized according to the following scale: the beginning/ emerging stage (scores between 2 - 4), the developing/proficient stage (4.5 - 6.5), and the strong/exemplary stage ( 7 - 9). Students were randomly selected from the beginning/emerging stage of the pre-test and from the developing/proficient stage to measure not only improvement on wide scale (between beginning/ emerging and strong/exemplary) but also on narrower scale (between developing/proficient and strong/exemplary). In other words, in the pre-test students with low as well as average scores were selected to view improvement between all levels (beginning-developing, beginning-strong, and developing-strong).

\section{Results and Discussion}

The experimental classes of SSCCJbeil and SSCC Beit Chabab were instructed on three essay genres, four tasks each. The tasks consisted of inquiry-based activities which required engagement, part of which came from ongoing assessment. Besides teacher's assessment, students assessed themselves and each other. They thought, researched, investigated, and analysed with each other before, during, and after the tasks in the classroom and from home via the blog. In answer to research question 3 whether the blog can be an effective assessment tool for inquiry-based strategies outside the classroom, the study proves that what connected the students of the same school outside the classroom was the blog. In addition, the blog also connected the two schools as the students could comment and assist each other from their homes. All the essay drafts were posted on the blog, making it easy from any of the learners to read, learn, ask, and teach.

The project commenced with a pre-test in the two schools to examine the mean differences and select the experimental and control sections. In SSCCJbeil, section A was the experimental, whereas section C was the control. In SSCC Beit Chabab, section A was the experimental, while section B was the control.

In SSCCJbeil, quantitatively, section C (control) scored insignificantly higher than section A (experimental) in pre-test with a score of $54.21 \%$ and $54.1 \%$ re- 
spectively. However, in all the summative tests, section A significantly excelled section C. In summative test one, section A scored $64.23 \%$, while section C scored $56.84 \%$. In summative test two, section A achieved $64.35 \%$, whereas section $\mathrm{C}$ achieved $60.26 \%$. In summative test three, section A reached the $67.44 \%$, while section $\mathrm{C}$ reached the $62.63 \%$.

Qualitatively, the experimental students developed considerably in the six traits from one test to another. For example, Stephanel, who represented the beginning/emerging stage of the experimental class, improved substantially in the six traits resulting in score augmentation which turned out the girl to be strong/ exemplary at the end of the project. Tatiana, Pietro, and Dolly, who represented the developing/proficient stage, also reached the strong/exemplary stage. Finally, Celine, from strong/exemplary stage, advanced in the traits and mastered essay writing.

On the other hand, the control students progressed but with limited development. They could not master the six traits like the experimental section. For example, Pia, who represented the beginning/emerging stage, developed in the six traits with difficulty. Jennifer, from the developing/proficient, remained in the same stage. Tatiana, from the strong/exemplary, progressed but her score was not as successful as Celine's of section A.

In SSCC, Beit Chabab, a similar scenario occurred. Quantitatively, section B (the control section) scored higher than section A (the experimental) in pre-test with $58.13 \%$ and $58.04 \%$ respectively. Nevertheless, in all the summative tests, section A achieved higher results. In test one, section A scored 52.39\%, while section B scored $50.63 \%$. In test two, section A achieved $67.17 \%$, while section B reached the $58.13 \%$. In test three, sections A and B scored $60.43 \%$ and $57.92 \%$ respectively.

Qualitatively, the experimental learners improved more than the control ones. For instance, Christel, representing the beginning/emerging stage developed to the developing/proficient. Nay and Lea, from the developing/proficient, became from the strong/exemplary. Marcelle, who represented the strong/exemplary stage, developed even more and rested in that stage.

The control section students had unpredictable results. For example, Maya, from the beginning/emerging stage, advanced to the developing/proficient but with difficulty with a score of 50\%. Elissa, representing the developing/proficient, was the only student of the control section who developed considerably reaching the strong/exemplary stage. Eliane, who came from strong/exemplary stage, deteriorated into the beginning/emerging and then rested in the developing/proficient stage.

The experimental sections surpassed the control sections quantitatively and qualitatively in both schools. Such achievement backs up Kahn and O'Rourke (2005), Cam (2006), Kuhlthau, Maniotes, and Caspari (2007), Cox, Webber, Levy and Stordy (2007), Kuhlthau, Maniotes, and Caspari (2007), and Coffman's (2009) notion that the IBLA is a successful means for improvement in language skills, specifically writing. 
Answering research question 4 about how the integration of IBLA, ongoing assessment, and technology enhance metacognition and learning for life, the experimental learners reached a level where they knew how and when to use particular strategies to solve their own learning problems. For instance, they could resort to each other and to technology such as the computer, mobile phone, and the Internet to search for content, vocabulary, and information on language structures without always referring to the teacher. Some of them even formed WhatsApp groups to deal with problems outside the classroom and to continue any piece of missing work related to unaccomplished tasks.

Some limitations arose in the study. Due to the mixed abilities of the students, some results might be inaccurate, specifically with the participants who were randomly selected for qualitative analysis. Also, due to the lack of good Internet connection and other technical malfunctions, some participants could not participate from homes and that resulted in varied cooperation from outside the classroom.

Much more research is still needed in the area of Inquiry-Based Learning, ongoing assessment, and blogging. However, implementing this method to improve essay writing in schools is suggested since it has proved successful. In addition, educators are suggested to modify the method through the years until it suits their classrooms and plan objectives.

As mentioned earlier, the blog is a useful tool for home assessment. Thus, to create a blog account, it is suggested to use blogger.com which is simple and user-friendly. In addition to blogging, teachers can use any technological tool that can have the capabilities of the blog. For instance, opening a group on Facebook can also function as a ground for forums and discussions. Therefore, teachers are supposed to see what is useful for them and for their students and at the same time what is available on order to take the right decisions.

For quantitative analysis of results, it is suggested to use the SPSS software which is accurate, user-friendly, and available in any tech shop. For qualitative analysis, the six traits rubric (Appendix E) can be utilized because it covers every aspect of essay writing starting from content to sentence fluency. Besides, the rubric can determine the examinee's level or stage of proficiency in order to measure development from one test to another.

\section{Conclusion}

The integration of IBLA and ongoing assessment has proved efficacious to help students improve in essay writing. Therefore, it is recommended to implement this method in classrooms. The application of this method should take place whenever writing is taught and at all levels during every academic year so that students and teachers alike get used to it. If every student is exposed to IBLA every year and for several years, the level of education increases and mastery of essay writing develops.

Practically, teachers are recommended to expose their students to IBLA at lower levels by designing tasks suitable for their ages. In addition, a well-organized 
plan with specific objectives should be inserted in the class syllabus so that this approach is part of the teaching curriculum rather than an isolated fragment. Otherwise, IBLA will function as an extra load which neither the teacher nor the students need.

To establish a home medium for assessment, educators are required to create a study blog which is, as Crie (2006) believes, a powerful tool for scaffolded learning as learners can collaborate and discuss effectively. Learners use it from home to assess and be assessed. However, educators should master blog work before exposing students to it to avoid its negative effects such as malfunctions and time loss. Later, in a pre-instructive stage, teachers train their students on how and when to utilize the blog.

To assure real and better results, it is highly recommended that teachers measure and analyse their students' results quantitatively and qualitatively. As Balram (2003) and Ritchie (2003) believe, the integration of both methods of analysis can be a powerful tool to inform and illuminate strategies and practices. Hence, the teacher can start analysing quantitatively and then back up the findings qualitatively.

\section{References}

Balram, S., Sholz, R. W., \& Olaf, T. (2003). Embedded Case Study Methods. Integrating Quantitative and Qualitative Knowledge. Thousand Oaks: Sage Publications, Inc.

Baron, N. S. (2008). Always On. New York, NY: Oxford University Press. https://doi.org/10.1093/acprof:oso/9780195313055.001.0001

Betts, J. D., \& Glogoff, S. J. (2005). Instructional Models for Using Weblogs in E-Learning: A Case Study from a Virtual and Hybrid Course. Syllabus 2004 Conference, San Francisco, CA.

Black, P., \& Wiliam, D. (1998). Inside the Black Box: Raising Standards through Classroom Assessment. Phi Delta Kappan, 80, 139-148.

Blake, R. J. (2008). Brave New Digital Classroom: Technology and Foreign Language Learning. Washington DC: Georgetown University Press.

Blood, R. (2000). Weblogs: A History and Perspective.

Brown, H. D. (2002). English Language Teaching in the "Post-Method" Era: Toward Better Diagnosis, Treatment, and Assessment. In J. C. Richards, \& W. A. Renandya (Eds.), Methodology on Language Teaching: An Anthology of Current Practice (pp. 9-17). Cambridge: Cambridge University Press. https://doi.org/10.1017/CBO9780511667190.003

Bruce, B. C., \& Bishop, A. P. (2001). Using the Web to Support Inquiry-Based Language Learning. In Y. S. Chuang, \& Wang, P. L. (Eds.), Proceedings of ROCMELIA 2001, the Fifth International Conference on Multimedia Language Instruction. Taipei: Crane. https://www.ideals.illinois.edu/bitstream/handle/2142/13342/Inquiry-based language 1 earning.pdf? sequence $=2$ \&isAllowed $=y$

Bybee, R. W. (2006). Scientific Inquiry and Science Teaching. In L. B. Flick, \& N. G. Lederman (Eds.), Scientific Inquiry and Nature of Science: Implications for Teaching, Learning and Teacher Education (pp. 1-14). Dordrecht: Springer.

Cam, P. (2006). 20 Thinking Tools: Collaborative Inquiry for the Classroom. Victoria: Acer Press.

Cappellini, M. (2005). Balancing Reading \& Language Learning: A Resource for Teaching 
English Language Learners, $K$-5. Portland, ME: Stenhouse Publishers.

Chapelle, C. A. (2003). English Language Learning and Technology. Amsterdam/ Philadelphia: John Benjamins Publishing Company. https://doi.org/10.1075/1llt.7

Chappuis, S., \& Stiggins, R. J. (2002). Classroom Assessment for Learning. Educational Leadership, 60, 40-43.

Chung, H., \& Beham, K. J. (2010). Peer Sharing Facilitates the Effect of Inquiry- Based Projects on Science Learning. The American Biology Teacher, 72, 24-29. https://doi.org/10.1525/abt.2010.72.1.7

Clark, I. L. (2008). Process. In I. L. Clark (Ed.), Concepts in Composition: Theory and Practice in the Teaching of Writing (pp. 1-70). Mahwah, NJ: Lawrence Erlbaum Associates Publishers.

Coffman, T. (2009). Engaging Students through Inquiry-Oriented Learning and Technology. Lanham, MD: Rowman \& Littlefield Education.

Cohen, L., Manion, L., \& Morrison, K. (2000). Research Methods in Education (5th ed.). London and New York, NY: Routledge Falmer. https://doi.org/10.4324/9780203224342

Cohen, L., Manion, L., \& Morrison, K. (2007). Research Methods in Education (6th ed.). London and New York, NY: Routledge Falmer.

Cox, A., Webber, S., Levy, P., \& Stordy, P. (2007). Blogging to Support Inquiry-Based Learning (IBL). Sheffield: Department of Information Studies, University of Sheffield.

Cram, B. (1995). Self-Assessment: From Theory to Practice. In G. Brindley (Ed.), Language Assessment in Action (282-292). Sydney: National Centre for English Language Teaching and Research.

Crie, M. (2006). Using Blogs to Integrate Technology in the Classroom. Teaching Today.

Dana, N. F., \& Yendol-Hoppey, D. (2008). The Reflective Educator's Guide to Professional Development: Coaching Inquiry-Oriented Learning Communities. Thousand Oaks, CA: Corwin Press.

Deboer, G. E. (2006). Historical Perspectives on Inquiry Teaching in Schools. In L.B. Flick, \& N.G. Lederman (Eds.), Scientific Inquiry and Nature of Science: Implications for Teaching, Learning and Teacher Education (pp. 17-35). Dordrecht: Springer.

Dodigovic, M. (2005). Artificial Intelligence in Second Language Learning: Raising Error Awareness. Clevedon: Multilingual Matters LTD.

Falk, B., \& Blumenreich, M. (2005). The Power of Questions: A Guide to Teacher and Student Research. Portsmouth, NH: Heinemann.

Falk, B., \& Margolin, L. (2005). Awakening the Questions within: Inquiry Research in an Elementary Classroom. Thinking Classrooms, 6, 6-14.

Frazier, D., \& Paulson, L. (1992). How Portfolios Motivate Reluctant Writers. Educational Leadership, 49, 62-65.

Genzola, A. E. (2010). Learner Autonomy through Web Logging: An Ict-Mediated Pedagogy in Elt. In A. Shafaei (Ed.), Frontiers of Language and Teaching (pp. 1-16). Boca Raton, FL: Universal-Publishers.

Godwin-Jones, J. (2003). Tag Clouds in the Blogosphere: Electronic Literacy and Social Networking. Language Learning \& Technology, 7, 13.

Greene, S., \& Lidinsky, A. (2012). From Inquiry to Academic Writing: A Text and Reader (2nd ed.). Boston and New York, NY: Bedford/St. Martin's.

Henning, J. E., Stone, J. M., \& Kelly, J. L. (2009). Using Action Research to Improve Instruction: An Interactive Guide for Teachers. New York, NY: Routledge.

Hewitt, H. (2005). Blog: Understanding the Information Reformation That's Changing 
Your World. Nashville, TN: Nelson Books.

Hou, H., Chang, K., \& Sung, Y. (2009). Using Blogs as a Professional Development Tool for Teachers: Analysis. Interactive Learning Environments, 17, 325-340. https://doi.org/10.1080/10494820903195215

Johnson, D. W., Johnson, R. T., \& Smith, K. A. (1991). Cooperative Learning: Increasing College Faculty Instructional Productivity. ASHE-ERIC Reports on Higher Education.

Kahn, P., \& O’Rourke, K. (2005). Understanding Enquiry-Based Learning. In T. Barrett, I. Mac Labhrainn, \& H. Fallon (Eds.), Handbook of Enquiry \& Problem Based Learning (pp. 1-12). Galway: CELT.

Katz, A., \& Olson, J. K. (2006). Strategies for Assessing Science and Language Learning. In A. K. Fathman, \& D. T. Crowther (Eds.), Science for English Language Learners: K-12 Classroom Strategies (pp.61-76). Arlington, TX: NSTA Press.

Kauchak, D. P. \& Eggen, P. D. (2003). Learning and Teaching: Research-Based Methods (4th ed.). Upper Saddle River, NJ: Pearson Education Inc.

Kemmis, S., \& McTaggart, R. (1992) The Action Research Planner (3rd ed.). Geelong: Deakin University Press.

Konicek-Moran, R. (2008). Everyday Science Mysteries: Stories for Inquiry-Based Science Teaching. Arlington, TX: NSTA Press.

Kuhlthau, C. C., Maniotes, L. K., \& Caspari, A. K. (2007). Guided Inquiry: Learning in the 21st Century. Wesport, CT and London: Libraries Unlimited.

Laksmi, E. D. (2006). “Scaffolding” Students' Writing in EFL Class: Implementing Process Approach. TEFLIN Journal, 17, 144-156.

Lassonde, C. A., \& Israel, S. E. (2010). Teacher Collaboration for Professional Learning: Facilitating Study, Research, and Inquiry Communities. San Francisco, CA: JosseyBass.

Legard, R., Keegan, J., \& Ward, K. (2003). In-Depth Interviews. In J. Ritchie, \& J. Lewis (Eds.), Qualitative Research Practice (pp. 138-169). Great Britain: Sage Publications.

Linn, R. L., \& Miller, M. D. (2005). Measurement and Assessment in Teaching (8th ed.). Upper Saddle River, NJ: Pearson Prentice Hall.

Lippman, J. N. (2008). Assessing Writing. In I. L. Clark (Ed.), Concepts in Composition: Theory and Practice in the Teaching of Writing (pp. 199-240). Mahwah, NJ: Lawrence Erlbaum Associates Publishers.

Mac Naughton, G., \& Hughes, P. (2008). Doing Action Research in Early Childhood Studies: A Step by Step Guide. Maidenhead: Open University Press.

Marczyk, G., DeMatteo, D., \& Festinger, D. (2005). Essentials of Research Design and Methodology. New York, NY: John Wiley \& Sons, Inc.

Marques de Sa, J. P. (2003). Applied Statistics Using SPSS, STATISTICA, and MATLAB. Berlin and New York, NY: Springer. https://doi.org/10.1007/978-3-662-05804-6

McDonough, J., \& McDonough, S. (1997). Research Methods for English Language Teachers. Great Britain: Arnold.

McNabb, D. E. (2010). Research Methods for Political Science: Quantitative and Qualitative Approaches (2nd ed.). New York, NY: M.E. Sharpe, Inc.

Mertler, C. A. (2006). Action Research: Teachers as Researchers in the Classroom. Thousand Oaks, CA: Sage Publications.

Mims, T. I. (2009). Collaborative Action Research for Culturally Responsive Teaching: A Case of Leadership, Teacher Experiences and Professional Learning. Ann Arbor, MI: ProQuest LLC.

Nora, J. (1999). Dissecting My Classroom. A Teacher Experiments with Action Research. 
Voices from the Fields (1999-2002). The Education Alliance at Brown University Database.

Nunan, D. (2004). Task-Based Language Teaching. Cambridge: Cambridge University Press. https://doi.org/10.1017/CBO9780511667336

O’Brien, R. (2001). An Overview of the Methodological Approach of Action Research. In R. Richardson (Ed.), Theory and Practice of Action Research. João Pessoa: Universidade Federal da Paraíba. (English Version). http://www.web.ca/ robrien/papers/arfinal.html

Ritchie, J. (2003). The Applications of Qualitative Methods to Social Research. In J. Ritchie, \& J. Lewis (Eds.), Qualitative Research Practice (pp. 24-46). Great Britain: Sage Publications.

Rolheiser, C., \& Ross, J. A. (2001). Student Self-Evaluation: What Research Says and What Practice Shows. In R. D. Small, \& A. Thomas (Eds.), Plain Talk about Kids (pp. 43-57). Covington, LA: Center for Development and Learning.

Scholz, R. W., \& Tietje, O. (2002). Embedded Case Study Methods: Integrating Quantitative and Qualitative Knowledge. Thousand Oaks, CA: Sage Publications. https://doi.org/10.4135/9781412984027

Somekh, B. (2011). Localisation or Globalization? The Dynamic Variations of Action Research. In N. Mockler, \& J. Sachs (Eds.), Rethinking Educational Practice through Reflexive Inquiry: Essays in Honour of Susan Groundwater-Smith (p. 31-48). London/ New York, NY: Springer. https://doi.org/10.1007/978-94-007-0805-1 3

Sun, Y. C. (2009). Voice Blog: An Exploratory Study of Language Learning. Language Learning \& Technology, 13, 88-103.

Sutman, F. X., Schmuckler, J. S., \&Woodfield, J. D. (2008). The Science Quest: Using Inquiry/Discovery to Enhance Student Learning. San Francisco, CA: Jossey-Bass.

Tierney, R., Carter, M., \& Desai, L. (1991). Portfolio Assessment in the Reading-Writing Classroom. Norwook, MA: Christopher-Gordon Publishers.

Wilson, N., \& McLean, S. (1994). Questionnaire Design: A Practical Introduction. Newtown Abbey: University of Ulster Press.

Wisker, G. (2001). The Postgraduate Research Handbooks. Great Britain: Palgrave.

Wu, W. (2007). Using Blogs in an EFL Writing Class. In Proceedings of the Department of Foreign Languages \& Literature (pp. 426-438). Chung Hua: Chung Hua University.

Zeichner, K., \&Noffke, S. (2001). Practitioner Research. In V. Richardson (Ed.), Handbook of Research on Teaching (pp. 298-332, 4th ed.). Washington DC: American Educational Research Association.

Zuber-Skerritt, O. (1996). Emancipatory Action Research for Organisational Change and Management Development. In O. Zuber-Skerritt (Ed.), New Directions in Action Research (pp. 83-105). London: Falmer. 
Submit or recommend next manuscript to SCIRP and we will provide best service for you:

Accepting pre-submission inquiries through Email, Facebook, LinkedIn, Twitter, etc. A wide selection of journals (inclusive of 9 subjects, more than 200 journals)

Providing 24-hour high-quality service

User-friendly online submission system

Fair and swift peer-review system

Efficient typesetting and proofreading procedure

Display of the result of downloads and visits, as well as the number of cited articles Maximum dissemination of your research work

Submit your manuscript at: http://papersubmission.scirp.org/

Or contact ojml@scirp.org 